\title{
High secreted protein acidic and rich in cysteine expression in peritumoral fibroblasts predicts better prognosis in patients with resectable gastric cancer
}

\author{
MASAO NAKAJIMA ${ }^{1}$, SHIGEFUMI YOSHINO ${ }^{2}$, SHINSUKE KANEKIYO ${ }^{1}$, \\ NORIKO MAEDA ${ }^{1}$, KAZUHIKO SAKAMOTO $^{1}$, RYOICHI TSUNEDOMI $^{1}$, NOBUAKI SUZUKI $^{1}$, \\ SHIGERU TAKEDA ${ }^{1}$, SHIGERU YAMAMOTO ${ }^{1}$, SHOICHI HAZAMA ${ }^{3}$, YOSHINOBU HOSHII ${ }^{4}$, \\ ATSUNORI OGA ${ }^{5}$, HIROSHI ITOH ${ }^{5}$, TOMIO UENO $^{6}$ and HIROAKI NAGANO ${ }^{1}$
}

${ }^{1}$ Department of Gastroenterological, Breast and Endocrine Surgery, Yamaguchi University Graduate School of Medicine;
${ }^{2}$ Oncology Center, Yamaguchi University Hospital; ${ }^{3}$ Department of Translational Research and Developmental
Therapeutics against Cancer, Yamaguchi University School of Medicine; ${ }^{4}$ Department of Diagnostic Pathology,
Yamaguchi University Hospital; ${ }^{5}$ Department of Molecular Pathology, Yamaguchi University Graduate School of
Medicine, Yamaguchi 755-8505; ${ }^{6}$ Department of Surgery, Kawasaki Medical School, Okayama 701-0192, Japan

Received April 20, 2017; Accepted September 22, 2017

DOI: $10.3892 / \mathrm{ol} .2017 .7418$

\begin{abstract}
Secreted protein acidic and rich in cysteine (SPARC) is an extracellular matrix glycoprotein that may serve an important role in epithelial-mesenchymal transition. Recent studies have demonstrated that SPARC status is a prognostic indicator in various cancer types; however, its value remains unclear in gastric cancer (GC). In the present study, the localization and prognostic impact of SPARC expression were evaluated in patients with GC. Immunohistochemical analysis of SPARC expression was performed in 117 surgically resected GC specimens, and the localization of SPARC positive cells, as well as the rassociation between SPARC expression and clinicopathological characteristics were evaluated. High SPARC expression was observed in 47 cases; the glycoprotein was localized in the peritumoral fibroblasts, but was rarely observed in the cytoplasm of cancer cells. Heterogeneity of SPARC expression was observed in 52 cases. High stromal SPARC expression was identified to be an independent predictor of more favorable prognosis (overall survival and recurrence free survival) in all patients $(\mathrm{P}<0.001)$. On subgroup analysis, this association remained significant in patients who received adjuvant chemotherapy, but not in patients who did not $(\mathrm{P}<0.001)$. Stromal SPARC expression predicts better prognosis in GC patients
\end{abstract}

Correspondence to: Professor Hiroaki Nagano, Department of Gastroenterological, Breast and Endocrine Surgery, Yamaguchi University Graduate School of Medicine, 1-1-1 Minami-Kogushi, Ube, Yamaguchi 755-8505, Japan

E-mail: hnagano@yamaguchi-u.ac.jp

Key words: gastric cancer, immunohistochemistry, prognosis, secreted protein acidic and rich in cysteine glycoprotein, chemosensitivity, stroma who underwent curative resection; this appears to be associated with improved response to chemotherapy.

\section{Introduction}

Gastric cancer (GC) is the fourth most common cancer worldwide and the second leading cause of cancer-related death (1). Surgical resection and adjuvant chemotherapy is the most recommended treatment for advanced GC; however, recurrence rates remain high (2). Therefore, identifying biomarkers that predict prognosis and response to chemotherapy in patients with GC remains a high priority. Secreted protein acidic and rich in cysteine (SPARC) is an extracellular matrix (ECM) glycoprotein and plays essential roles in normal tissue remodeling and wound repair (3). In cancerous tissue, SPARC has been associated with epithelial-mesenchymal transition (EMT) through mediating interactions with different ECM components and growth factors, as well as regulating the properties of invasion and metastasis (4-7).

Many studies have reported that SPARC is expressed in various types of cancers; however, the relationship between its expression pattern and disease prognosis is still under investigation. Some studies concluded that overexpression of SPARC is associated with disease progression and poor prognosis in biliary tract cancer, esophageal squamous cell cancer, pancreatic cancer, head and neck cancer, and breast cancer (8-12); however, others reported that overexpression of SPARC is associated with better prognosis in colorectal cancer (13). In GC, it remains unclear whether or not overexpression of SPARC is associated with better prognosis. Recently, SPARC localization was reported to be a key factor when assessing the relationship between SPARC expression and prognosis in various cancers $(8,14)$. Furthermore, a relationship between SPARC expression and chemosensitivity has been reported $(8,14-17)$. To date, as for GC, patterns of SPARC 
localization are still undetermined ;moreover, few studies have assessed the relationship between the localization of SPARC positive cells and prognosis in terms of chemosensitivity.

In this study, we examined the localization of SPARC in GC cells and investigated the relationship between SPARC expression and prognosis in GC patients who underwent curative resection. We further compared prognosis in patients who received adjuvant chemotherapy vs. those who did not.

\section{Materials and methods}

$G C$ resected specimens. We collected surgically resected GC specimens from 117 consecutive patients who underwent curative surgery (excluding patients with stage IA) between 2004 and 2010 at Yamaguchi University Hospital. Resected specimens were fixed in formalin and embedded in paraffin prior to immunohistochemistry (IHC). The use of resected samples was approved by the Human Ethics Committee of the Graduate School of Medicine, Yamaguchi University. Written informed consent was obtained from all patients included in this study.

SPARC IHC. Three anti-SPARC antibodies, ON1-1 (Invitrogen, Carlsbad, CA, USA), SPARCL1 (ProteinTech Group, Inc., Chicago, IL, USA), and AON-5031 (Santa Cruz Biotechnology, Santa Cruz, CA, USA), were tested to select the most suitable for SPARC IHC. The AON-5031 monoclonal antibody used in the study by Inoue et al (18), Zhao et al (19) and Zhang et al (20) was chosen because it was least prone to nonspecific staining.

To determine the cells that express SPARC in GC, we performed IHC using large tissue sections that contained both noncancerous and cancerous tissues. We examined the expression of SPARC in non-neoplastic gastric tissues, in the cytoplasm of the primary cancer cells, and in the stromal cells surrounding the cancer cells. Resected specimens were cut into $4-\mu \mathrm{m}$ slices and deparaffinized using routine techniques. Antigen retrieval was performed in $10 \mathrm{mM}$ sodium citrate buffer ( $\mathrm{pH} \mathrm{6.0)}$ heated at $95^{\circ} \mathrm{C}$ in a steamer for $20 \mathrm{~min}$. After blocking endogenous peroxidase activity with a $3 \%$ aqueous $\mathrm{H}_{2} \mathrm{O}_{2}$ solution for $5 \mathrm{~min}$, the sections were incubated with serum-free protein block (Dako, Carpinteria, CA, USA) for $10 \mathrm{~min}$ and the sections were incubated with an anti-SPARC monoclonal antibody (AON-5031) at a final concentration of $0.1 \mathrm{mg} / \mathrm{ml}$ for $60 \mathrm{~min}$. Labeling was detected with the Envision Plus Detection kit (DAKO) following the manufacturer's protocol, and the staining was visualized by incubating with DAB for 5 min followed by counterstaining with hematoxylin. Sections of human placenta were used as positive controls; for negative controls, the primary antibody was substituted with non-immunized immunoglobulin G (Vector Laboratories Inc. Burlingame, CA, USA).

Evaluation of SPARC expression. Staining was analyzed by 2 certified pathologists of Japan blinded to any knowledge of the clinicopathological parameters. SPARC-positive cells were located only in the peritumoral stroma; therefore, we further evaluated the various components of the cancerous lesion (Fig. 1). The IHC for SPARC was scored and categorized as previously reported by Zhao et al (19); briefly, the proportions of cells with SPARC expression were rated as follows: $0, \leq 5 \%$ positive cells; 1 , 6-25\% positive cells; $2,26-50 \%$ positive cells; and $3, \geq 51 \%$ positive cells. The intensity of staining varied from weak to strong and was classified on a scale of 0 (no staining); 1 (weak staining, light yellow); 2 (moderate staining, yellowish brown), and 3 (strong staining, brown). The staining index (SI) was calculated as the product of the staining intensity score and the proportion of positive cells; we obtained SI scores of $0,1,2,3,4,6$ or 9 . An SI score $\geq 4$ was defined as high SPARC expression, while a score $\leq 3$ was defined as low SPARC expression. The heterogeneity of SPARC expression was defined as previously reported by Lee et al (21). Briefly, samples with $>5 \%$ and $\leq 50 \%$ stromal cells with a SPARC IHC intensity of 2 or 3 were considered to be heterogeneous, whereas the others were considered to be homogeneous SPARC expression in the large section.

Double staining. Some tissue sections were double-stained with anti- $\alpha$-smooth muscle actin ( $\alpha$-SMA) antibody (1:125; ab5694; Abcam, Cambridge, MA, USA) and anti-SPARC antibody, in the same way described above, to analyze the relationship between SPARC expression and $\alpha$-SMA-positive fibroblasts.

Statistical analysis. All data were expressed as medians with interquartile ranges. Baseline patient characteristics were compared by using the Wilcoxon-Mann-Whitney test for continuous variables and Fisher's exact test for non-continuous variables. Overall survival (OS) and recurrence free survival (RFS) rates were analyzed using the Kaplan-Meier method with log-rank tests. The independent significance of each factor was determined by the Cox proportional hazards model, following inclusion of prognostic variables showing a significant $\mathrm{P}$-value on univariate analysis. On multivariate analyses of all patients, all variables (differentiation, $\mathrm{pT}$ stage, $\mathrm{pN}$ stage, vascular invasion, UICC stage, adjuvant chemotherapy, and stromal SPARC expression) were included to predict significant risk factors for OS, RFS, and invasion to vascular systems.

To adjust for significant differences in the baseline characteristics of patients, propensity score matching was used. Propensity scores were calculated accounting for all factors significantly associated with the staining index through a logistic regression model based on the following 9 covariates: Age, sex, differentiation, depth of wall invasion, invasion into the venous system, invasion into the lymphatic system, nodal status, TNM stages, and adjuvant chemotherapy. Propensity scores represented the likelihood of a patient expressing high SPARC relative to low SPARC; patients of these 2 groups were then paired 1:1 based on propensity scores using the 'greedy' nearest neighbor matching algorithm without replacement. A caliper size of $0.2 x \log$ (standard deviation of the propensity score) was utilized. Standardized differences were estimated before and after matching to evaluate the balance of covariates. Following 1:1 propensity score matching, OS and RFS between the matched 2 groups were examined by Kaplan-Meier estimates using the log rank test.

In general, all statistical analyses were 2-tailed, and $\mathrm{P}<0.05$ was considered to indicate a statistically significant difference.. All statistical analyses were performed with JMP Pro 11.0 software (SAS Institute, Cary, NC, USA). 


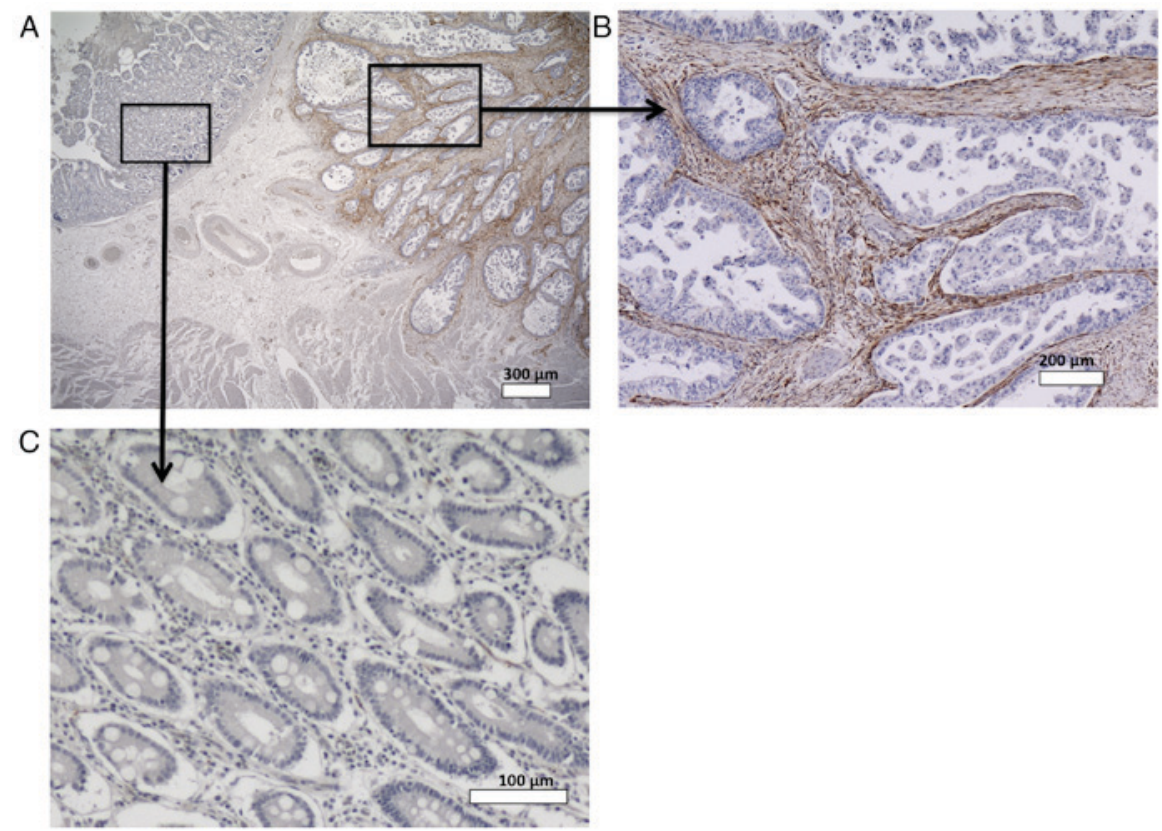

Figure 1. Immunohistochemistry of SPARC in (A) gastric cancer and normal gastric tissues (the same tissue section is shown (magnification, x2). (B) SPARC is localized in the peritumoral fibroblasts (magnification, $\mathrm{x} 4$ ); however, it is rarely localized in the cytoplasm of (C) cancer cells and normal gastric tissue (magnification, x10). SPARC, secreted protein acidic and rich in cysteine.
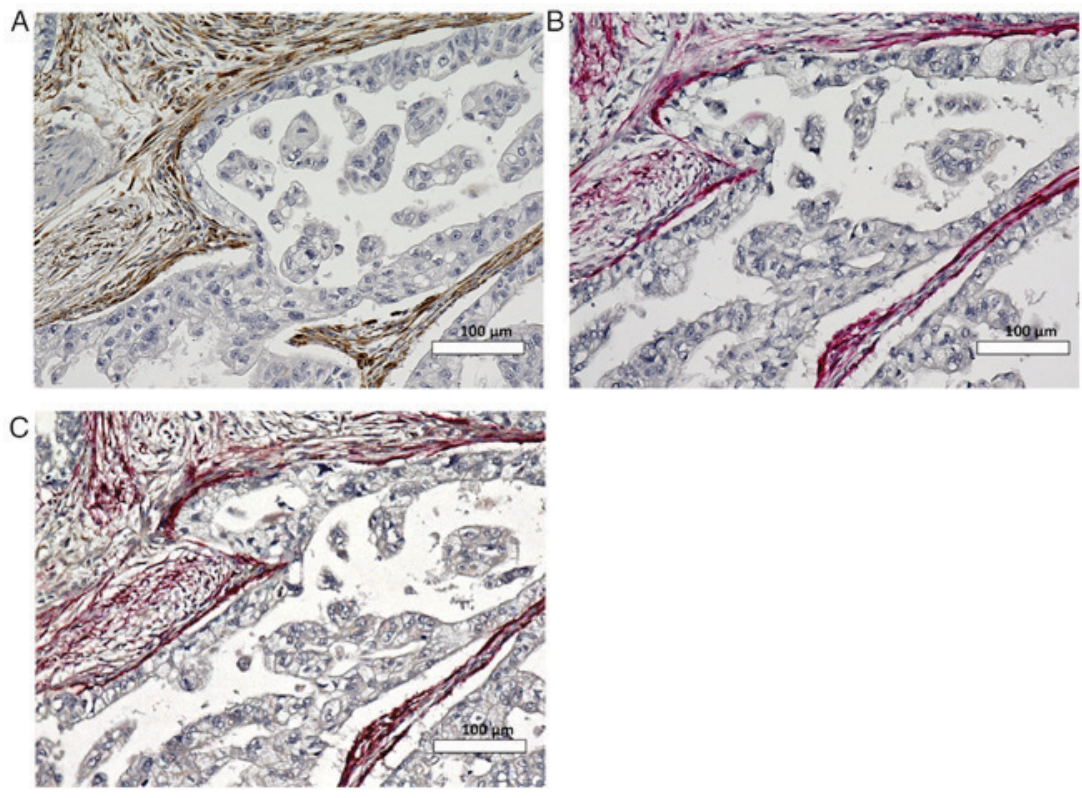

Figure 2. Immunohistochemistry of (A) SPARC (magnification, x10) and (B ) $\alpha$-SMA (magnification, x10) using (C) the double staining method (magnification, x10). $\alpha$-SMA-positive fibroblasts are localized in peritumoral cells, and express SPARC more intensely than $\alpha$-SMA-negative fibroblasts. SPARC, secreted protein acidic and rich in cysteine; $\alpha$-SMA, $\alpha$-smooth muscle actin.

\section{Results}

SPARC expression and localization in the resected $G C$ specimens. Fig. 1 shows SPARC expression in GC and normal gastric tissues. In normal tissues, SPARC staining was observed in the nerve bundle and endothelial cells; however, SPARC staining was rare in the gastric mucosa and stromal cells. In cancer tissues, SPARC was observed in the cytoplasm of fibroblasts surrounding the cancer cells, but was rare in the cytoplasm of cancer cells themselves.
In certain SPARC-positive sections, cancer cells were surrounded by anti- $\alpha$-SMA antibody-stained fibroblasts that were strongly positive for SPARC. Fig. 2 shows SPARC and $\alpha$-SMA expression using the double staining method. $\alpha$-SMA strong-positive fibroblasts were localized to peritumoral cells; these cells expressed SPARC more intensely than $\alpha$-SMA negative fibroblasts.

Intensity and heterogeneity of SPARC expression of the resected $G C$ specimens. Among the 117 patients we evaluated, the number 

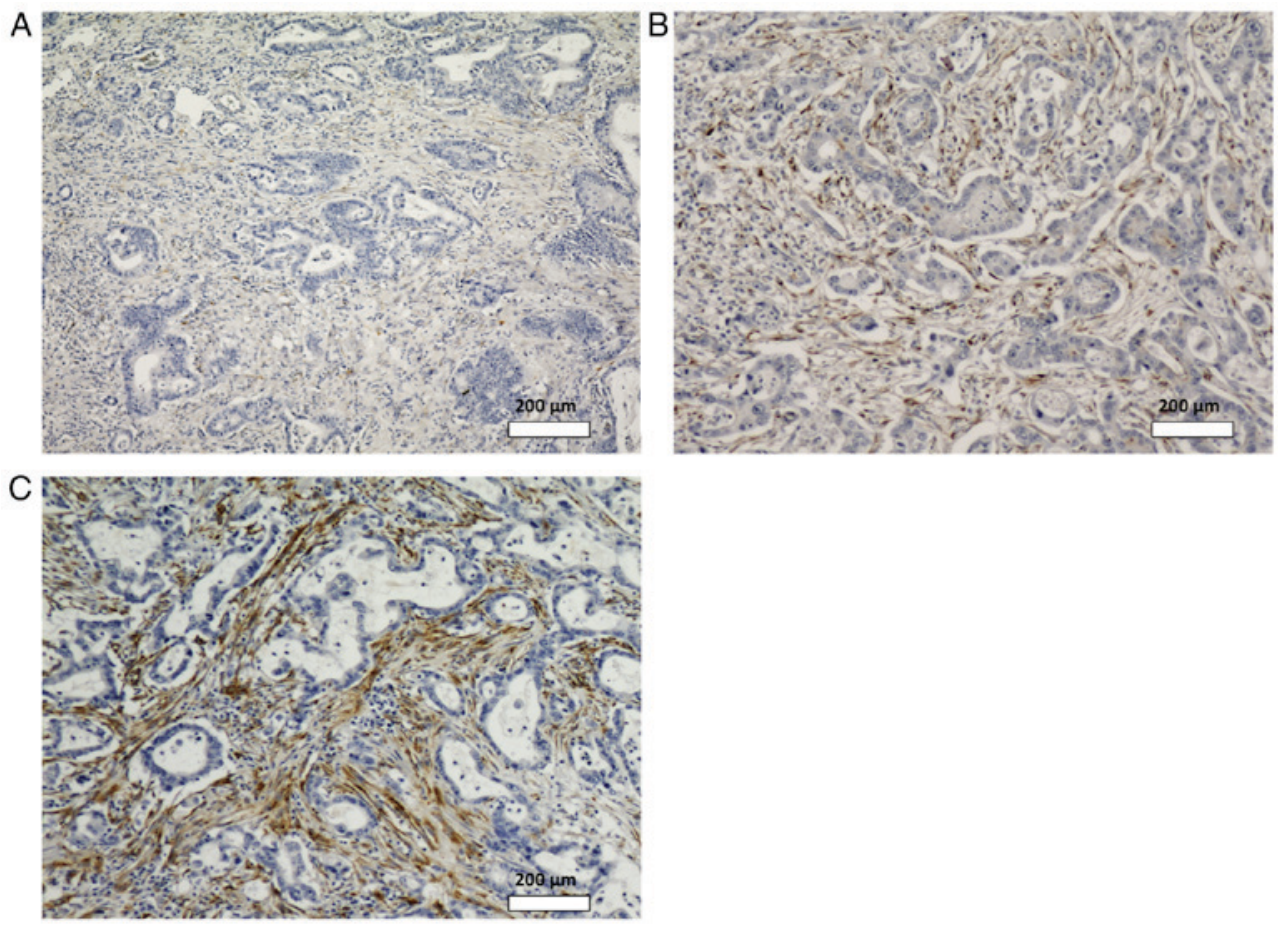

Figure 3. Examples of gastric cancer cases with stromal SPARC staining indexes of (A) 0 (magnification, x4), (B) 4 (magnification, x4), and (C) 9 (magnification, $x 4)$. SPARC, secreted protein acidic and rich in cysteine.

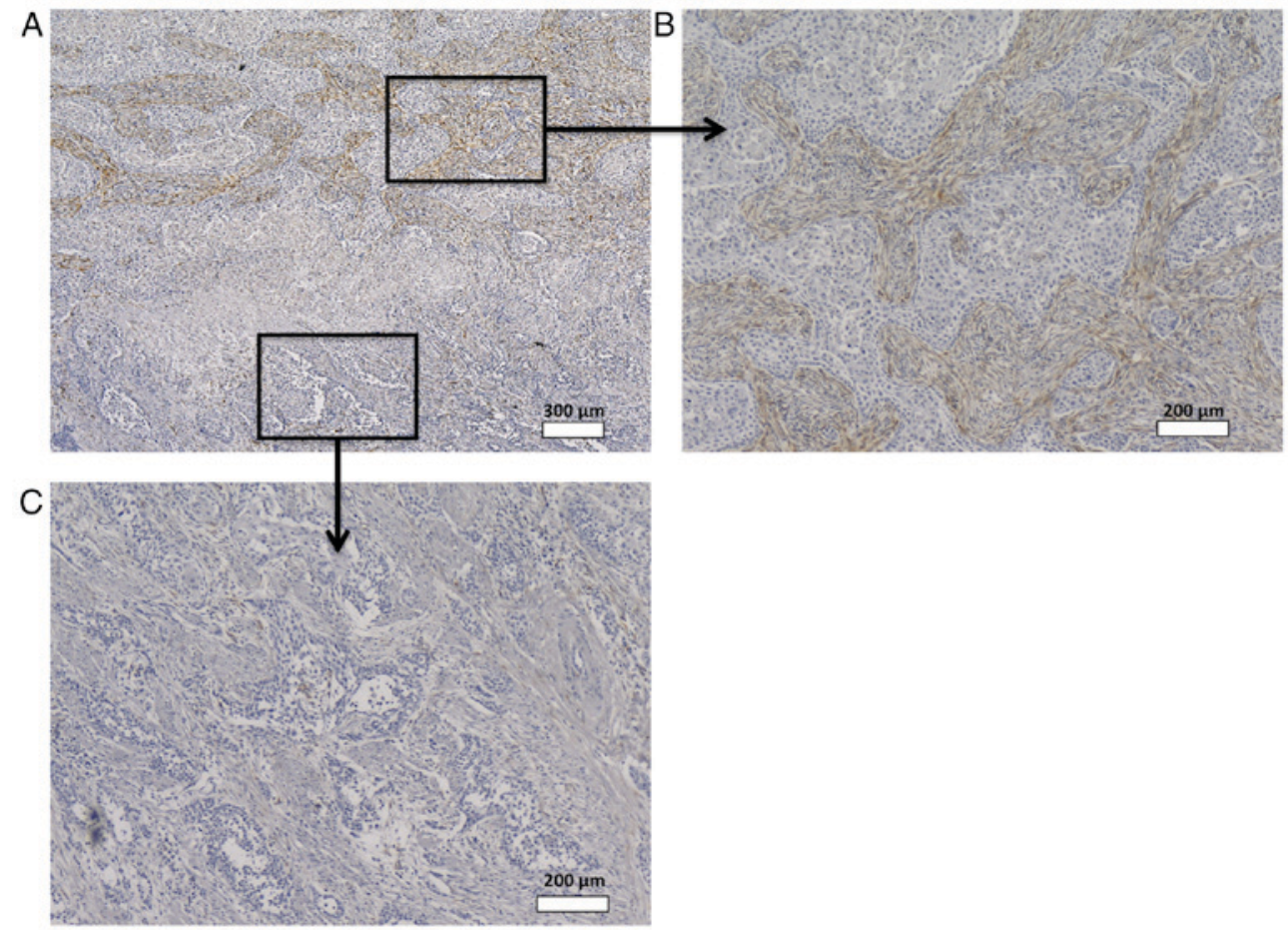

Figure 4. (A) The heterogeneity of SPARC expression in the same tissue section (maginification, $x 2$ ). (B) High SPARC expression in peritumoral fibroblasts are observed in one lesion (maginification, $\mathrm{x} 4$ ); however, (C) no SPARC expression of peritumoral fibroblasts is observed in another lesion (magnification, $\mathrm{x} 4$ ). SPARC, secreted protein acidic and rich in cysteine.

of cases with SPARC SI scores of $0,1,2,3,4,6$, and 9 were 24 , $9,21,16,11,29$, and 7, respectively. High SPARC expression (SI $\geq 4$ ) was observed in 47 cases (40\%). Fig. 3 shows examples of stromal SPARC expression with SI scores of 0,4 , and 9, respectively. Heterogeneity of staining was observed in 52 cases (44\%), among which 23 showed high SPARC expression. Fig. 4 shows a representative case of heterogeneous SPARC expression.

Relationship between stromal SPARC expression and clinicopathological factors of cohorts before and after 
Table I. Clinicopathological characterristics of study group and association with SPARC expression before and after propensity matching.

\begin{tabular}{|c|c|c|c|c|c|c|}
\hline \multirow[b]{3}{*}{ Characteristic } & \multicolumn{3}{|c|}{ Before propensity matching } & \multicolumn{3}{|c|}{ After propensity matching } \\
\hline & \multicolumn{2}{|c|}{ SPARC Scoring index } & \multirow[b]{2}{*}{ P-value } & \multicolumn{2}{|c|}{ SPARC Scoring index } & \multirow[b]{2}{*}{ P-value } \\
\hline & $\leqq 3(\mathrm{~N}=70)$ & $\geqq 4(\mathrm{~N}=47)$ & & $\leqq 3(\mathrm{~N}=36)$ & $\geqq 4(\mathrm{~N}=36)$ & \\
\hline Age (median) & 66 & 63 & 0.046 & 65 & 64 & 0.959 \\
\hline Gender & & & 0.546 & & & 1.000 \\
\hline Male & 50 & 31 & & 23 & 23 & \\
\hline Female & 20 & 16 & & 13 & 13 & \\
\hline Histology & & & 0.013 & & & 1.000 \\
\hline Intestinal & 22 & 26 & & 16 & 16 & \\
\hline Diffuse & 48 & 21 & & 20 & 20 & \\
\hline Depth of wall invasion & & & 0.696 & & & 0.799 \\
\hline $\mathrm{T} 1, \mathrm{~T} 2$ & 51 & 20 & & 10 & 12 & \\
\hline $\mathrm{T} 3, \mathrm{~T} 4$ & 45 & 32 & & 26 & 24 & \\
\hline Lymph node metastasis & & & 0.331 & & & 1.000 \\
\hline Negative & 22 & 19 & & 11 & 12 & \\
\hline Positive & 48 & 28 & & 25 & 24 & \\
\hline TNM stages & & & 0.703 & & & 0.813 \\
\hline I, II & 40 & 29 & & 18 & 20 & \\
\hline III, IV & 30 & 18 & & 18 & 16 & \\
\hline Venous invasion & & & 0.839 & & & 0.786 \\
\hline Negative & 23 & 14 & & 8 & 10 & \\
\hline Positive & 47 & 33 & & 28 & 26 & \\
\hline Lymphatic invasion & & & 0.761 & & & 0.735 \\
\hline Negative & 8 & 4 & & 6 & 4 & \\
\hline Positive & 62 & 43 & & 30 & 32 & \\
\hline Adjuvant chemotherapy & & & 0.437 & & & 1.000 \\
\hline Negative & 24 & 20 & & 15 & 14 & \\
\hline Positive & 46 & 27 & & 21 & 22 & \\
\hline
\end{tabular}

SPARC, secreted protein acidic and rich in cysteine; TNM, tumor node metastasis.

propensity score matching. The patients' characteristics are summarized in Table I. All patients underwent R0 resection, and $76(66 \%)$ had pathological lymph node metastases. Seventy-three patients received adjuvant chemotherapy $(60 \%)$, including 49 with S-1, 20 with tegafur-uracil, and 24 with paclitaxel (22 patients received more than 1 regimen). Age and histology were significantly different between the high- and low-SPARC groups before propensity matching; however, 36 couples were matched after propensity score-matched analysis, and all their variables were balanced (Table I).

Relationship between SPARC expression and survival after surgery. The 5-year OS rate was $87 \%$ (95\% confidence interval (CI), 73-94\%) in the high SPARC group, and 62\% (95\% CI, $50-71 \%$ ) in the low SPARC group. The hazard ratio (HR) for death in the high SPARC group compared to the low SPARC group was 0.294 (95\% CI, 0.109-0.666, log-rank $\mathrm{P}=0.004)$ (Fig. 5). The 5-year RFS rate was $87 \%$ (95\% CI, 74-97\%) in the high SPARC group, and 59\% (95\% CI, 47-70\%) in the low SPARC group. The HR for recurrence in the high SPARC group compared to the low SPARC low group was $0.305(95 \%$ CI, 0.113-0.689, log-rank P=0.004) (Fig. 5). There was no relationship between the heterogeneity of the SPARC expression and prognosis.

Tables II and III show the univariate and multivariate analyses of OS and RFS, respectively, using Cox regression. Univariate analysis revealed that low stromal SPARC expression, UICC stage, invasion into the lymphatic system, invasion into the venous system, and the depth of wall invasion were associated with poor prognosis. Multivariate logistic regression analysis demonstrated that only low stromal SPARC expression remained a poor prognostic factor for OS (HR, 3.884; 95\% CI, 1.691-10.514, $\mathrm{P}=0.0009$ ); furthermore, low stromal SPARC expression and invasion into the lymphatic system were poor prognostic factors for RFS independent of other clinicopathological factors. Multivariate logistic regression analysis revealed that high SPARC expression had no 
Table II. The univariate and multivariate analysis for overall survival using Cox regression analysis.

\begin{tabular}{|c|c|c|c|c|c|c|c|}
\hline \multirow[b]{2}{*}{ Covariates } & \multirow[b]{2}{*}{$\mathrm{N}$} & \multicolumn{3}{|c|}{ Univariate analysis } & \multicolumn{3}{|c|}{ Multivariate analysis } \\
\hline & & Hazard ratio & $95 \% \mathrm{CI}$ & P-value & Hazard ratio & $95 \% \mathrm{CI}$ & P-value \\
\hline Differentiation & & & & 0.893 & & & 0.377 \\
\hline Intestinal & 69 & 1 & & & 1 & & \\
\hline Diffuse & 45 & 0.954 & $0.481-1.939$ & & 0.721 & $0.353-1.507$ & \\
\hline Depth of wall invasion & & & & 0.015 & & & 0.718 \\
\hline $\mathrm{T} 1, \mathrm{~T} 2$ & 40 & 1 & & & 1 & & \\
\hline $\mathrm{T} 3, \mathrm{~T} 4$ & 77 & 2.727 & $1.204-7.309$ & & 1.217 & $0.433-3.808$ & \\
\hline Lymph node metastasis & & & & 0.060 & & & 0.998 \\
\hline Negative & 41 & 1 & & & 1 & & \\
\hline Positive & 76 & 2.117 & $0.970-5.290$ & & 0.998 & $0.259-3.548$ & \\
\hline TNM stages & & & & 0.001 & & & 0.08 \\
\hline$\leqq \mathrm{II}$ & 69 & 1 & & & 1 & & \\
\hline$\geqq$ III & 48 & 3.063 & $1.523-6.422$ & & 2.572 & $0.9-8.99$ & \\
\hline Venous invasion & & & & 0.007 & & & 0.113 \\
\hline Negative & 37 & 1 & & & 1 & & \\
\hline Positive & 80 & 3.167 & $1.331-9.331$ & & 2.184 & $0.842-6.896$ & \\
\hline Lymphatic invasion & & & & 0.002 & & & 0.054 \\
\hline Negative & 12 & 1 & & & 1 & & \\
\hline Positive & 105 & 1.656 & $1.632-5.363$ & & 3.718 & $0.912-9.325$ & \\
\hline SPARC expression (H/L) & & & & 0.002 & & & $<0.001$ \\
\hline Low & 70 & 1 & & & 1 & & \\
\hline High & 47 & 0.294 & $0.109-0.666$ & & 0.258 & $0.095-0.592$ & \\
\hline Adjuvant chemotherapy & & & & 0.169 & & & 0.385 \\
\hline Negative & 44 & 1 & & & 1 & & \\
\hline Positive & 73 & 1.679 & $0.808-3.817$ & & 0.615 & $0.213-1.884$ & \\
\hline
\end{tabular}

TNM, tumor node metastasis; SPARC, secreted protein acidic and rich in cysteine; H, high; L, low; CI, confidence interval.

significant association with venous or lymphatic invasion $(\mathrm{OR}$, $0.439 ; 95 \%$ CI, 0.065-2.380, $\mathrm{P}=0.439$ ).

Chemotherapy sensitivity and SPARC expression. Among the 117 patients who underwent R0 surgery, 73 patients (62\%) received adjuvant chemotherapy. Metastatic lymph nodes, higher TNM stage, deeper wall invasion, and venous and lymphatic invasion were more common in patients treated with adjuvant chemotherapy than in patients without adjuvant chemotherapy $(\mathrm{P}<0.05$ respectively, data not shown); however, there was no difference in SI scores between the groups.

Fig. 6 shows the relationship between SPARC expression and prognosis according to adjuvant chemotherapy. In patients who received adjuvant chemotherapy, better prognosis was observed in the high SPARC group (for OS: HR, 3.54; 95\% CI, 1.34-12.2, P=0.0091; for RFS: HR, 4.09; 95\% CI, 1.57-13.9, $\mathrm{P}=0.0026$ ). However, in patients without adjuvant chemotherapy, there was no relationship between prognosis and SPARC expression. Regarding the type of chemotherapy regimen, only in the patients with the taxane-containing chemotherapy regimen, there was significant difference about RFS between the two groups.
Propensity score matching analysis. As previously mentioned, 36 couples were matched after propensity score-matched analysis. All of the baseline clinicopathological characteristics between the high and low SPARC groups were balanced, and OS and RFS remained longer in the high SPARC group (Fig. 5).

\section{Discussion}

The present study revealed 3 important clinical findings. First, SPARC is expressed in the cytoplasm of fibroblasts (especially $\alpha$-SMA-positive fibroblasts) surrounding the cancer cells; however, SPARC was rarely expressed in the cytoplasm of cancer cells themselves or in the stromal cells of normal tissue in GC patients. Second, high SPARC expression was observed in $40 \%$ of GC samples, and heterogeneity of SPARC expression was observed in 44\%. Third, high stromal SPARC expression was found to be an independent prognostic factor for more favorable OS and RFS in GC patients who underwent curative resection; this relationship was significant in patients who received adjuvant chemotherapy.

Previously, various studies found that SPARC is upregulated in GC; however, there are discrepancies regarding the 

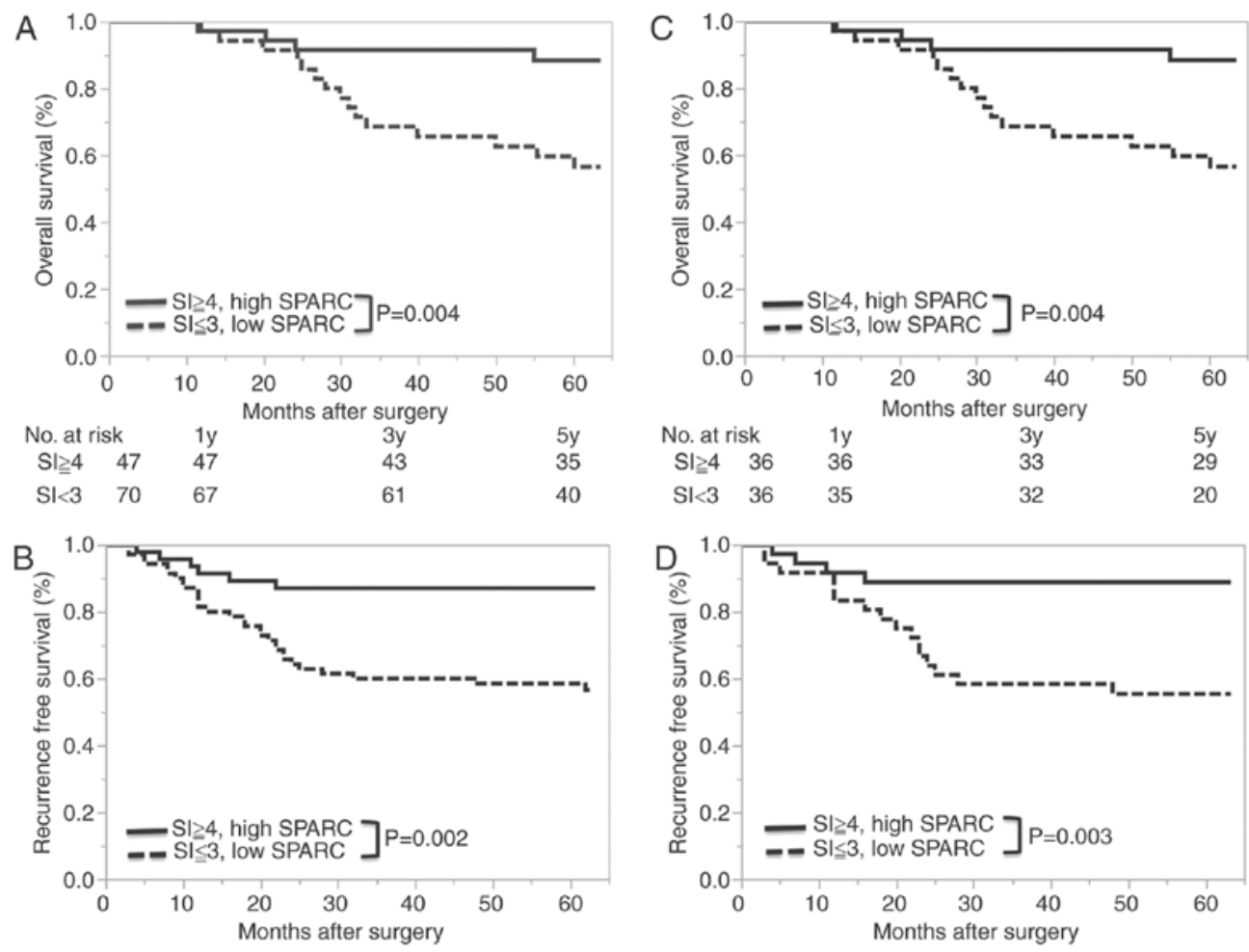

\begin{tabular}{ccccc}
\multicolumn{2}{l}{ No. at risk } & $1 \mathrm{y}$ & $3 \mathrm{y}$ & $5 \mathrm{y}$ \\
$\mathrm{SI} \geq 4$ & 47 & 43 & 39 & 32 \\
$\mathrm{SI}<3$ & 70 & 61 & 46 & 34
\end{tabular}

\begin{tabular}{ccccc}
\multicolumn{2}{c}{ No. at risk } & $1 \mathrm{y}$ & $3 \mathrm{y}$ & $5 \mathrm{y}$ \\
$\mathrm{SI} \geq 4$ & 36 & 34 & 30 & 27 \\
$\mathrm{SI}<3$ & 36 & 33 & 21 & 17
\end{tabular}

Figure 5. Survival curves (A and C, overall survival; B and D, recurrence-free survival) for patients with gastric cancer after curative surgery according to SPARC expression before (A and B) and after (C and D) propensity matching. In both groups, significant differences in survival are observed by log-rank test. SPARC, secreted protein acidic and rich in cysteine.
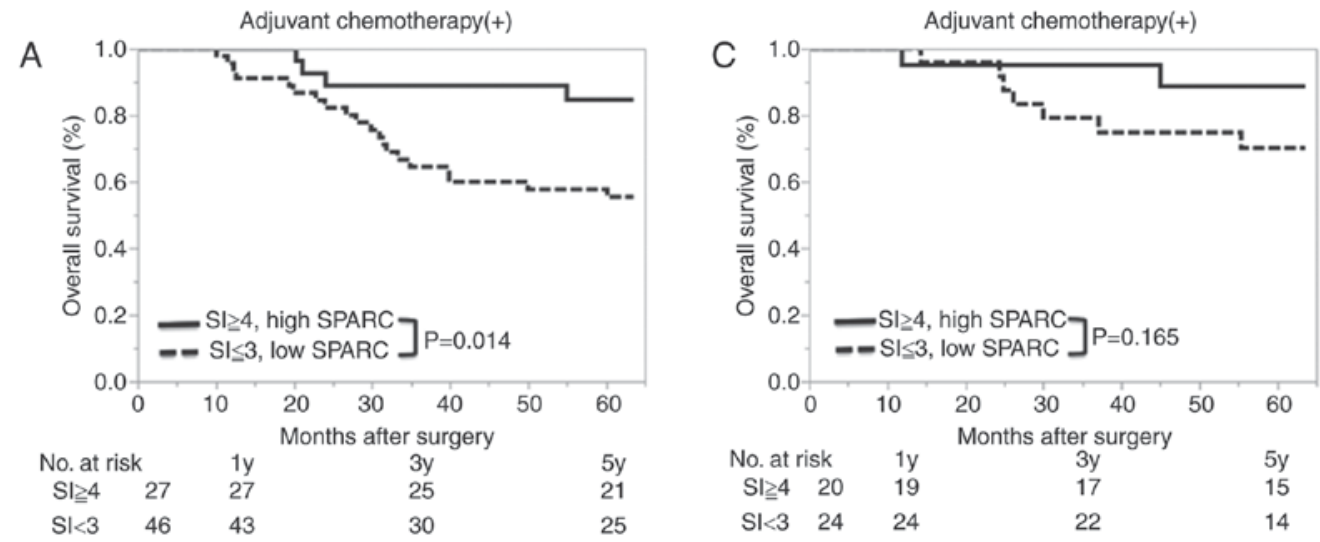

\begin{tabular}{|c|c|c|c|}
\hline \multirow[b]{2}{*}{ No. at risk } & \multicolumn{3}{|c|}{ Months after surgery } \\
\hline & $1 y$ & $3 y$ & $5 y$ \\
\hline $\mathrm{SI} \geqq 4 \quad 2$ & 19 & 17 & 15 \\
\hline $\mathrm{SI}<3 \quad 2$ & 24 & 22 & 1 \\
\hline
\end{tabular}
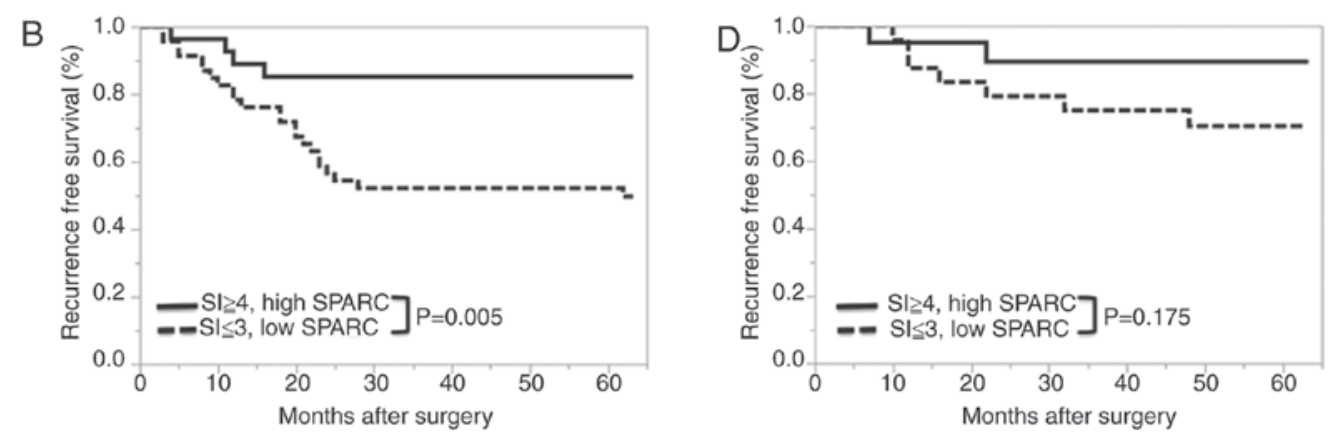

\begin{tabular}{lllll}
\multicolumn{2}{l}{ No. at risk } & $1 y$ & $3 y$ & $5 y$ \\
$\mathrm{SI} \geqq 4$ & 27 & 27 & 24 & 20 \\
$\mathrm{SI}<3$ & 46 & 38 & 25 & 23
\end{tabular}

\begin{tabular}{ccccc}
\multicolumn{2}{c}{ No. at risk } & $1 y$ & $3 y$ & $5 y$ \\
$\mathrm{SI} \geqq 4$ & 20 & 19 & 13 & 12 \\
$\mathrm{SI}<3$ & 24 & 23 & 18 & 12
\end{tabular}

Figure 6. Survival curves (A and C, overall survival; B and D, recurrence free survival) for patients with (A and B) or without (C and D) adjuvant chemotherapy according to SPARC expression. Significant differences in survival were observed only in patients who received adjuvant chemotherapy. SPARC, secreted protein acidic and rich in cysteine. 
Table III. The univariate and multivariate analysis for relapse free survival using Cox regression analysis.

\begin{tabular}{|c|c|c|c|c|c|c|c|}
\hline \multirow[b]{2}{*}{ Covariates } & \multirow[b]{2}{*}{$\mathrm{N}$} & \multicolumn{3}{|c|}{ Univariate analysis } & \multicolumn{3}{|c|}{ Multivariate analysis } \\
\hline & & Hazard ratio & $95 \% \mathrm{CI}$ & P-value & Hazard ratio & $95 \% \mathrm{CI}$ & P-value \\
\hline Differentiation & & & & 0.926 & & & 0.265 \\
\hline Intestinal & 69 & 1 & & & 1 & & \\
\hline Diffuse & 45 & 0.969 & $0.502-1.915$ & & 0.672 & $0.339-1.363$ & \\
\hline Depth of wall invasion & & & & 0.029 & & & 0.754 \\
\hline $\mathrm{T} 1, \mathrm{~T} 2$ & 40 & 1 & & & 1 & & \\
\hline $\mathrm{T} 3, \mathrm{~T} 4$ & 77 & 2.369 & $1.085-5.925$ & & 1.178 & $0.434-3.449$ & \\
\hline Lymph node metastasis & & & & 0.051 & & & 0.871 \\
\hline Negative & 41 & 1 & & & 1 & & \\
\hline Positive & 76 & 2.087 & $0.997-4.907$ & & 0.904 & $0.255-3.008$ & \\
\hline TNM stages & & & & 0.004 & & & 0.219 \\
\hline$\leqq \mathrm{II}$ & 69 & 1 & & & 1 & & \\
\hline$\geqq$ III & 48 & 2.770 & $1.391-5.808$ & & 1.873 & $0.703-5.84$ & \\
\hline Venous invasion & & & & 0.007 & & & 0.094 \\
\hline Negative & 37 & 1 & & & 1 & & \\
\hline Positive & 80 & 3.167 & $1.331-9.331$ & & 2.204 & $0.883-6.749$ & \\
\hline Lymphatic invasion & & & & 0.002 & & & 0.039 \\
\hline Negative & 12 & 1 & & & 1 & & \\
\hline Positive & 105 & 1.656 & $1.475-4.912$ & & 4.223 & $1.078-4.398$ & \\
\hline SPARC expression $(\mathrm{H} / \mathrm{L})$ & & & & 0.003 & & & $<0.001$ \\
\hline Low & 70 & 1 & & & 1 & & \\
\hline High & 47 & 0.305 & $0.113-0.689$ & & 0.232 & $0.086-0.527$ & \\
\hline Adjuvant chemotherapy & & & & 0.056 & & & 0.994 \\
\hline Negative & 44 & 1 & & & 1 & & \\
\hline Positive & 73 & 2.009 & $0.982-4.528$ & & 0.996 & $0.367-2.939$ & \\
\hline
\end{tabular}

TNM, tumor node metastasis; SPARC, secreted protein acidic and rich in cysteine; H, high; L, low; CI, confidence interval.

reported localization of SPARC in the stomach. Some papers reported a differential expression of SPARC, mainly in the cytoplasm of GC cells $(19,22,23)$; whereas, others found that SPARC exists mainly in the stromal cells surroundings the GC cells (24-26). These discrepancies may be attributed to the method of IHC (choice of primary antibody, antibody dilutions and staining protocols) and/or the selection of tissue specimens. We established a precise IHC method to determine SPARC levels in gastric tissue while reducing nonspecific staining, and demonstrated that SPARC is expressed in the fibroblasts surrounding the cancer cells. Previous studies in other cancer types $(13,24-26)$ are consistent with our results; this provides strong evidence that our methods are reliable. Moreover, SPARC was mainly expressed in $\alpha$-SMA-positive peritumoral fibroblasts. A proportion of $\alpha$-SMA-positive fibroblasts are reported to be cancer-associated fibroblasts derived from bone marrow (27), signifying a possible relationship between these types of fibroblasts and SPARC; however, this requires further study.

Although high stromal SPARC expression was a significant prognostic factor in patients who received adjuvant chemotherapy, no such relationship was observed in those without adjuvant chemotherapy. Our findings are inconsistent with those described in previous reports $(19,22-24)$. This may be explained by the localization and heterogeneity of SPARC expression as they relate to chemosensitivity. Recent reports suggest that only stromal SPARC expression plays an important role in prognosis $(8,14)$. Moreover, our study was the first to describe heterogeneity of SPARC expression, which in our case was found in $44 \%$ of our samples. Zhao et al (19) evaluated SPARC expression using tissue microarray sections, and reported that cases with high SPARC expression in tumoral and peritumoral cells showed poor prognosis; however, they never evaluated the heterogeneity and location of SPARC expression (24). Therefore, it is very important to use large tissue sections to be able to assess the localization and heterogeneity of SPARC expression in the tumor milieu. To our knowledge, our study is the largest series that used large tissue sections to evaluate 'stromal' SPARC expression in GC patients. Moreover, our study is the first to use propensity-matched analysis for evaluating the relationship between SPARC expression and prognosis. Therefore, we propose that our study is more reliable compared to those previously reported. Hence, high SPARC expression in peritumoral fibroblasts is likely associated with better prognosis. 
The next challenge is to explain why SPARC affects prognosis. There are two possibilities; one is association with EMT and the other is chemosensitivity. Previous reports indicated that high SPARC expression is correlated with a lower potential for EMT in experimental models $(4,5,28,29)$. Our study showed that high stromal SPARC expression was associated with better RFS for the first time; however, we could not demonstrate a relationship between the SPARC expression and vascular invasion by multivariate analysis. On the other hand, high stromal SPARC expression was found to be associated with better prognosis in patients with adjuvant chemotherapy but not in those without. Therefore, we hypothesized that SPARC improves prognosis because of an association with improved chemosensitivity. Previous studies reported the possibility of SPARC being associated with chemosensitivity in various cancers $(8,14-17,30)$. As for GC, there was only 1 study that evaluated the relationship between SPARC expression and prognosis from the viewpoint of chemosensitivity (17); however, that study included patients with preoperative chemotherapy and evaluated the association between SPARC expression in cancer cells per se and OS. Our findings raise the possibility that stromal SPARC increases chemosensitivity in patients with GC. It has been reported that the antitumor activity of nab-paclitaxel, an albumin-bound paclitaxel, may be enhanced by binding to SPARC-positive stroma surrounding the cancer cells (14,31-33). Like nab-paclitaxel, other cytotoxic drugs may accumulate in the high SPARC-expressing stroma surroundings GC cells (17). Further study is required to explore this notion and its associated mechanisms.

Our study is limited by the fact that it was small and retrospective. To overcome this limitation, prospective multicenter studies with standardized IHC methods are required to evaluate stromal SPARC expression using large tissue sections.

In conclusion, our study revealed that high stromal SPARC expression is an independent and favorable prognostic factor, in terms of OS and RFS, in GC patients who undergo curative resection. High SPARC expression may increase the tumor's sensitivity to adjuvant chemotherapy through accumulating the anti-cancer drugs in the SPARC positive fibroblasts surrounding the cancer cells. Hence, evaluating stromal SPARC expression may help develop individualized therapy in GC patients.

\section{Acknowledgements}

The authors would like to thank Ms. Akiko Sano, Ms. Kaori Kaneyasu, Ms. Madoka Kajiwara and Ms. Yuko Takenouchi for their technical assistance with this study.

\section{References}

1. Lordick F, Allum W, Carneiro F, Mitry E, Tabernero J, Tan P, Van Cutsem E, van de Velde C and Cervantes A: Unmet needs and challenges in gastric cancer: The way forward. Cancer Treat Rev 40: 692-700, 2014.

2. Noh SH, Park SR, Yang HK, Chung HC, Chung IJ, Kim SW, Kim HH, Choi JH, Kim HK, Yu W, et al: Adjuvant capecitabine plus oxaliplatin for gastric cancer after D2 gastrectomy (CLASSIC): 5-year follow-up of an open-label, randomised phase 3 trial. Lancet Oncol 15: 1389-1396, 2014.

3. Bradshaw AD and Sage EH: SPARC, a matricellular protein that functions in cellular differentiation and tissue response to injury. J Clin Invest 107: 1049-1054, 2001.
4. Yin J, Chen G, Liu Y, Liu S, Wang P, Wan Y, Wang X, Zhu J and Gao H: Downregulation of SPARC expression decreases gastric cancer cellular invasion and survival. J Exp Clin Cancer Res 29: 59, 2010.

5. Zhang J, Wang P, Zhu J, Wang W, Yin J, Zhang C, Chen Z, Sun L, Wan Y, Wang X, et al: SPARC expression is negatively correlated with clinicopathological factors of gastric cancer and inhibits malignancy of gastric cancer cells. Oncol Rep 31: 2312-2320, 2014.

6. Brekken RA and Sage EH: SPARC, a matricellular protein: At the crossroads of cell-matrix communication. Matrix Biol 19: 816-827, 2001.

7. Rivera LB, Bradshaw AD and Brekken RA: The regulatory function of SPARC in vascular biology. Cell Mol Life Sci 68: 3165-3173, 2011.

8. Nakashima S, Kobayashi S, Sakai D, Tomokuni A, Tomimaru Y, Hama N, Wada H, Kawamoto K, Marubashi S, Eguchi H, et al: Prognostic impact of tumoral and/or peri-tumoral stromal SPARC expressions after surgery in patients with biliary tract cancer. J Surg Oncol 110: 1016-1022, 2014.

9. Nagai MA, Gerhard R, Fregnani JH, Nonogaki S, Rierger RB, Netto MM and Soares FA: Prognostic value of NDRG1 and SPARC protein expression in breast cancer patients. Breast Cancer Res Treat 126: 1-14, 2011.

10. Mantoni TS, Schendel RR, Rödel F, Niedobitek G, Al-Assar O, Masamune A and Brunner TB: Stromal SPARC expression and patient survival after chemoradiation for non-resectable pancreatic adenocarcinoma. Cancer Biol Ther 7: 1806-1815, 2008.

11. Yamashita $\mathrm{K}$, Upadhay S, Mimori $\mathrm{K}$, Inoue $\mathrm{H}$ and Mori $\mathrm{M}$ : Clinical significance of secreted protein acidic and rich in cystein in esophageal carcinoma and its relation to carcinoma progression. Cancer 97: 2412-2419, 2003.

12. Wang HY, Li YY, Shao Q, Hou JH, Wang F, Cai MB, Zeng YX and Shao JY: Secreted protein acidic and rich in cysteine (SPARC) is associated with nasopharyngeal carcinoma metastasis and poor prognosis. J Transl Med 10: 27, 2012.

13. Chew A, Salama P, Robbshaw A, Klopcic B, Zeps N, Platell C and Lawrance IC: SPARC, FOXP3, CD8 and CD45 correlation with disease recurrence and long-term disease-free survival in colorectal cancer. PLoS One 6: e22047, 2011.

14. Von Hoff DD, Ramanathan RK, Borad MJ, Laheru DA, Smith LS, Wood TE, Korn RL, Desai N, Trieu V, Iglesias JL, et al: Gemcitabine plus nab-paclitaxel is an active regimen in patients with advanced pancreatic cancer: A phase I/II trial. J Clin Oncol 29: 4548-4554, 2011

15. Takeno A, Takemasa I, Doki Y, Yamasaki M, Miyata H, Takiguchi S, Fujiwara Y, Matsubara K and Monden M: Integrative approach for differentially overexpressed genes in gastric cancer by combining large-scale gene expression profiling and network analysis. Br J Cancer 99: 1307-1315, 2008.

16. Tai IT, Dai M, Owen DA and Chen LB: Genome-wide expression analysis of therapy-resistant tumors reveals SPARC as a novel target for cancer therapy. J Clin Invest 115: 1492-1502, 2005.

17. Gao YY, Han RB, Wang X, Ge SH, Li HL, Deng T, Liu R, Bai M, Zhou LK, Zhang XY, et al: Change of SPARC expression after chemotherapy in gastric cancer. Cancer Biol Med 12: 33-40, 2015.

18. Inoue M, Senju S, Hirata S, Ikuta Y, Hayashida Y, Irie A, Harao M, Imai K, Tomita Y, Tsunoda T, et al: Identification of SPARC as a candidate target antigen for immunotherapy of various cancers. Int J Cancer 127: 1393-1403, 2010.

19. Zhao ZS, Wang YY, Chu YQ, Ye ZY and Tao HQ: SPARC is associated with gastric cancer progression and poor survival of patients. Clin Cancer Res 16: 260-268, 2010.

20. Zhang JL, Chen GW, Liu YC, Wang PY, Wang X, Wan YL, Zhu J, Gao HQ, Yin J, Wang W and Tian ML: Secreted protein acidic and rich in cysteine (SPARC) suppresses angiogenesis by down-regulating the expression of VEGF and MMP-7 in gastric cancer. PLoS One 7: e44618, 2012.

21. Lee HE, Park KU, Yoo SB, Nam SK, Park DJ, Kim HH and Lee HS: Clinical significance of intratumoral HER2 heterogeneity in gastric cancer. Eur J Cancer 49: 1448-1457, 2013.

22. Jeung HC, Rha SY, Im CK, Shin SJ, Ahn JB, Yang WI, Roh JK, Noh SH and Chung HC: A randomized phase 2 study of docetaxel and S-1 versus docetaxel and cisplatin in advanced gastric cancer with an evaluation of SPARC expression for personalized therapy. Cancer 117: 2050-2057, 2011.

23. Wang CS, Lin KH, Chen SL, Chan YF and Hsueh S: Overexpression of SPARC gene in human gastric carcinoma and its clinic-pathologic significance. Br J Cancer 91: 1924-1930, 2004. 
24. Franke K, Carl-McGrath S, Röhl FW, Lendeckel U, Ebert MP, Tänzer M, Pross M and Röcken C: Differential expression of SPARC in intestinal-type gastric cancer correlates with tumor progression and nodal spread. Transl Oncol 2: 310-320, 2009.

25. Maeng HY, Song SB, Choi DK, Kim KE, Jeong HY, Sakaki Y and Furihata C: Osteonectin-expressing cells in human stomach cancer and their possible clinical significance. Cancer Lett 184: 117-121, 2002.

26. Wang L, Yang M, Shan L, Qi L, Chai C, Zhou Q, Yao K, Wu H and Sun W: The role of SPARC protein expression in the progress of gastric cancer. Pathol Oncol Res 18: 697-702, 2012.

27. Quante M, Tu SP, Tomita H, Gonda T, Wang SS, Takashi S, Baik GH, Shibata W, Diprete B, Betz KS, et al: Bone marrow-derived myofibroblasts contribute to the mesenchymal stem cell niche and promote tumor growth. Cancer Cell 19: 257-272, 2011.

28. Zhang L, Sah B, Ma J, Shang C, Huang Z and Chen Y: A prospective, randomized, controlled, trial comparing occult-scar incision laparoscopic cholecystectomy and classic three-port laparoscopic cholecystectomy. Surg Endosc 28: 1131-1135, 2014.

29. Puolakkainen PA, Brekken RA, Muneer S and Sage EH: Enhanced growth of pancreatic tumors in SPARC-null mice is associated with decreased deposition of extracellular matrix and reduced tumor cell apoptosis. Mol Cancer Res 2: 215-224, 2004.
30. Sinn M, Sinn BV, Striefler JK, Lindner JL, Stieler JM, Lohneis P, Bischoff S, Bläker H, Pelzer U, Bahra M, et al: SPARC expression in resected pancreatic cancer patients treated with gemcitabine: Results from the CONKO-001 study. Ann Oncol 25: 1025-1032, 2014.

31. Desai N, Trieu V, Damascelli B and Soon-Shiong P: SPARC expression correlates with tumor response to albumin-bound paclitaxel in head and neck cancer patients. Transl Oncol 2: 59-64, 2009.

32. Hidalgo M, Plaza C, Musteanu M, Illei P, Brachmann CB, Heise C, Pierce D, Lopez-Casas PP, Menendez C, Tabernero J, et al: SPARC expression did not predict efficacy of nab-paclitaxel plus gemcitabine or gemcitabine alone for metastatic pancreatic cancer in an exploratory analysis of the phase III MPACT trial. Clin Cancer Res 21: 4811-4818, 2015.

33. Schneeweiss A, Seitz J, Smetanay K, Schuetz F, Jaeger D, Bachinger A, Zorn M, Sinn HP and Marmé F: Efficacy of nab-paclitaxel does not seem to be associated with SPARC expression in metastatic breast cancer. Anticancer Res 34: 6609-6615, 2014.

(7) (3) This work is licensed under a Creative Commons Attribution-NonCommercial-NoDerivatives 4.0 International (CC BY-NC-ND 4.0) License. 